\title{
The Effect of Psychological Well-being and Subjective Well-being on Grade Point Average with Self-compassion as Variable Moderating
}

\author{
Yuningsih \\ \{yuningsih.1961@feb.unila.ac.id\}
}

Management Department, Faculty of Business and Economics, Universitas Lampung

\begin{abstract}
Psychological well-being focuses on eudaimonic well-being, while Subjective well-being focuses on the way individuals evaluate their lives by involving evaluations on two components, namely cognitive and affective. Self-compassion is the ability of individuals to pay attention and care for themselves when experiencing challenges, problems, and difficulties in life and is able to see it as a part of human life experiences, one of the factors that can affect GPA is psychological well-being, subjective well-being and self-compassion. The purpose of this study is to determine the effect of Psychological Well-being and Subjective Well-being on GPA collages student with Self-compassion as variable moderating. The results show that there are positive and significant effects between Psychological wellbeing, Subjective well-being and Self-compassion variable is a quasi-moderating. This illustrates that Psychological well-being and Subjective well-being can increase GPA, and self-compassion can support Psychological well-being and Subjective well-being to increase a GPA collages student
\end{abstract}

Keywords: Psychological Well-being, Subjective Well-being, Self-compassion, Grade Point Average collages student

\section{Introduction}

Well-being is something that almost everyone is looking for because it includes many positive things, such as feeling happy, healthy, good social relationships, etc. Unfortunately, welfare seems to be decreasing, at least for students who are just entering early adulthood, and improving welfare can be difficult without knowing what to do and how to do it. Well-being is an important aspect to be developed, especially for students[1].

Psychological well-being focuses on eudaimonic well-being or prosperity derived from the struggle to achieve self-actualization, which in the process will be greatly influenced by the talents, values, and needs of individuals in living life, which is the fulfillment of human potential and meaningful life [2]. Psychological well-being involves feelings developed in the face of life's challenges, such as pursuing goals, growing and developing as a person, and building bonds to others[3]. Whereas subjective well-being focuses on the way individuals evaluate their lives. Subjective well-being involves evaluating two components, namely cognitive and affective [4]. [5] state that happiness is a part of subjective well-being which is a subjective view of the whole life that an individual has one factor that can affect psychological well-being and Subjective well-being is self-compassion. [1] explain that pampering yourself by giving love and care when facing challenges, problems, or difficulties in life can increase well-being in individuals.

Psychological well-being is a positive mental health criterion that is important to develop in humans, because individuals who have Psychological well-being can make positive assessments of themselves, be able to establish a warm relationship with others, be able to control the external environment, have a purpose in life, able to withstand social pressure, and able to optimize their potential. According to[6] There are factors considered as key elements of Psychological well-being. Namely Autonomy, Environmental mastery. Personal growth. Positive relations with others. Purpose in life. Self-acceptance.

Subjective well-being is how individuals evaluate their lives. Subjective well-being involves evaluating two components, namely cognitive and affective. The high level of subjective well-being is marked by cognitive evaluation, in the form of high life satisfaction and affective evaluation in the form of high positive affect, and low negative affect[4]. Subjective well-being is a broad concept regarding the evaluation of one's life or emotional experience, which is a combination of high life satisfaction, high positive affect, and low negative 
affect. Someone who has a high level of subjective well-being has the ability to manage emotions, and deal with problems well. Conversely people who have a low level of subjective-well-being tend to feel unhappy, full of negative thoughts and feelings that cause anxiety, anger, and even risk of depression [7].

Self-compassion is the ability of individuals to provide goodness and concern for themselves when experiencing challenges, problems, and difficulties in life and to understand that all challenges, problems, and difficulties in life are part of the experience of human life. Self-compassion is able to protect individuals from various negative emotions such as stress, anxiety and depression and balance them with positive emotions and affect the improvement of psychological well-being [8].

Self-compassion is the main source of psychological well-being. The hedonic approach (subjective well-being) that is looking for happiness by involving happy experiences and avoiding pain, when individuals are able to accept themselves as they are and learn to become a better person [8].

Well-being is one of the determining aspects of Academic Achievement. In the campus world students are required to compete in obtaining academic achievements, where the benchmark is the achievement index. Academic achievement is the result of lessons obtained from learning activities in schools or colleges that are cognitive and are usually determined through measurement and assessment.

Assessment on students is usually obtained from mid test grades, assignments and assignments that are relevant to learning in tertiary institutions. The success of students in the academic field is marked by academic achievements, shown through the achievement index (IP) and cumulative achievement index (GPA). Cumulative achievement index is a number that shows the cumulative achievement or progress of student learning starting from the first semester to the most recent semester (Academic Regulations of Univeristy of Lampung's).

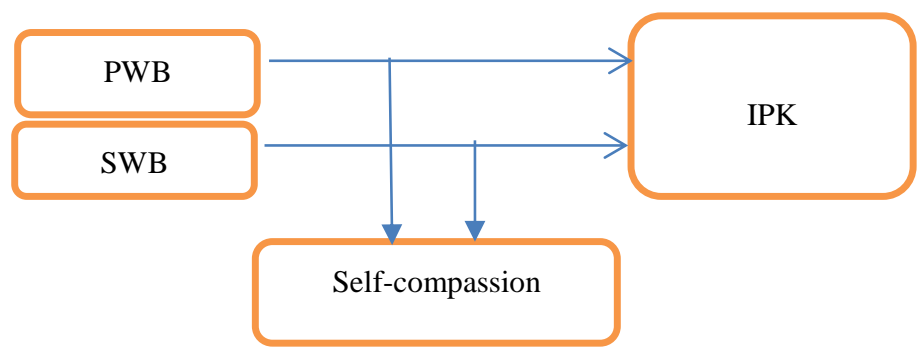

Fig.1. Framework

\section{Hypothesis}

1. PWB Hypothesis

- first hypothesis states that PWB has a positive effect on GPA

- Second hypothesis which states, the self compassion has a positive effect on the GPA

- Third hypothesis which states that self compassion is a quasi variable and has positive effect

\section{SWB Hypothesis}

- first hypothesis states that SWB has a positive effect on GPA

- Second hypothesis which states, the self compassion has a positive effect on the GPA

- Third hypothesis which states that self compassion is a quasi variable and has positive effect

\section{Research Methods}

The research method is a series of systematic procedures that need to be observed when conducting a research, so that the results of the research can be justified. The research method used in this study is a quantitative correlational method that aims to detect the extent to which variations in a factor are related to variations in one or more other factors based on the correlation coefficient [9]. The variables to be tested for correlation are the 
Effect of Psychological Well-being and Subjective Well-being on the Cumulative Achievement Index with Selfcompassion as a moderating variable on University of Lampung's students.

\section{Sample and Sampling Technique}

The population of this research is the University of Lampung students. The sample in this study amounted to 202 people. The technique used in this study was non-probability sampling where each individual in the population did not have the same opportunity to be chosen as the research sample. The technique used was purposive sampling. Researchers used certain characteristics in this study [10].

\section{Scale}

Psychological Well-being [6]. 18 items assess 6 dimensions of psychological well-being, three items per dimension: autonomy, environmental mastery, positive relations with others, personal growth, purpose in life, and self-acceptance. Subjective well-being use Satisfaction with Life Scale (SWLS; [11]. Participants rated 5 items and Positive and Negative Affect Scales (PANAS; [12]. The PANAS is a 20 item measures 10 positive and 10 negative. Self-compassion[13]. 25 items assess 6 dimensions of Self-compassion, Self-Kindness, SelfJudgment, Common Humanity, Isolation, Mindfulness, Over-identified GPA uses a scale based on the academic regulations of University of Lampung's in 2017, as follows:

Table 1. Point of GPA

\begin{tabular}{|c|c|}
\hline GPA & Point \\
\hline$>3,00$ & Very Good \\
\hline $2,50-2,99$ & Good \\
\hline $2.00-2,49$ & Sufficient \\
\hline $1,50-1,99$ & Deficient \\
\hline$<1,49$ & Very Deficient \\
\hline
\end{tabular}

\section{Result and discussion}

\section{Validity}

Measurement of validity is using factor analysis with SPSS, Kaiser-Meyer-Olkin (KMO) and Measure of Sampling Adequacy (MSA) $\geq 0.5$ Considered valid and research can be further researched (Santoso, 2002).

Table 2. Test Validity Results

\begin{tabular}{|l|l|l|l|}
\hline & PWB & SWB & Self-Compassion \\
\hline KMO & 0,707 & 0,792 & 0,625 \\
\hline Approx Chi Square & 821.109 & 1944.080 & 1415.981 \\
\hline Df & 153 & 300 & 325 \\
\hline Sig & 0,000 & 0,000 & 0,000 \\
\hline
\end{tabular}

According validity test indicates that the Kaiser- Meyer- Olkin (KMO) of PWB (X1), SWB (X2), SelfCompassion (X3) indicators, demonstrate the value $>0.5$. which mean that all indicators used is valid and can be processed for the next steps.

\section{Reliability}

Reliability test is a test to measure a questionnaire which is an indicator of a variable. A questionnaire is reliable if the answer to the question is consistent over time. Reliability measurement in this study were carried out by means of one-shot test or only one measurement. Measurements were only conduct once then the results will be compared with other statements or reliability were measured with the Cronbach's alpha statistical test. A variable is realistic if the Cronbach's alpha value is $>0.60$. 
Table 3. Test Reliability results

\begin{tabular}{|l|l|l|l|}
\hline & Cronbach's Alpha & $\begin{array}{l}\text { Cronbach's Alpha Based on } \\
\text { Standardized Items }\end{array}$ & N of Items \\
\hline PWB & 0,760 & 0,752 & 18 \\
\hline SWB & 0,826 & 0,843 & 25 \\
\hline Self-compassion & 0,689 & 0,695 & 26 \\
\hline
\end{tabular}

The result of the reliability test show that all PWB (X1), SWB (X2), Self-Compassion (X3) variables were reliable because they have crossed the limit of the reliability coefficient $(0.6)$ thus the items in each of these variable concepts were used as a measuring instrument.

\section{Model Assessment Test}

To analyze the data, the researcher applies a multiple regression method. The analysis technique uses regression analysis with the equation:

Table 4. Assessment Test

\begin{tabular}{|c|c|c|c|c|c|c|}
\hline \multirow{2}{*}{\multicolumn{2}{|c|}{ Model }} & \multicolumn{2}{|c|}{$\begin{array}{c}\text { Unstandardized } \\
\text { Coefficients }\end{array}$} & \multirow{2}{*}{$\begin{array}{c}\begin{array}{c}\text { Standardized } \\
\text { Coefficients }\end{array} \\
\text { Beta }\end{array}$} & \multirow[b]{2}{*}{$\mathrm{t}$} & \multirow[b]{2}{*}{ Sig. } \\
\hline & & $\mathrm{B}$ & Std. Error & & & \\
\hline \multirow[t]{4}{*}{1} & (Constant) & 3.439 & 3.412 & & 1.008 & .315 \\
\hline & PWB & 1.218 & .829 & 1.326 & 1.470 & .043 \\
\hline & $\mathrm{SC}$ & 1.649 & .840 & 1.356 & 1.962 & .041 \\
\hline & Moderated 1 & .250 & .203 & 1.628 & 1.231 & .029 \\
\hline
\end{tabular}

a. Dependent Variable: Y

F : 39.922 Sig. : 0.000 R Square : 0.394 Adjusted R Square : 0.385

$$
\begin{aligned}
& Y=a+b 1 X 1+b 2 X 3+b 3 \mathrm{M} 1 \\
& Y=3.439+1.326 X 1+1.356 X 3+0,265 M 1
\end{aligned}
$$

Based on Table 4, the sig value of PWB regression coefficient is 0.043 smaller than the significant value of 0.05 , it means that the PWB has significantly affect the firm GPA. The first hypothesis states that PWB has a positive effect on GPA, is accepted. The sig value of SC regression coefficient is 0.041 smaller than the significant value of 0.05 . It suggests that self compassion has significantly affect the GPA, so the second hypothesis which states, the self compassion has a positive effect on the GPA, accepted. The sig value of Moderated regression analysis coefficient is 0.029 smaller than the significant value of 0.05 . third hypothesis which states that self compassion is a quasi variable and has positive effect on the GPA is accepted.

Table 3 shows the R Square value of 0.394 with Adjusted R2 of 0.385 . This shows that all independent and moderated variables, can explain $38.5 \%$ of the variation magnitude in the GPA. $61.5 \%$ of variations are explained by other variables that are not used in this study. Table 2 also shows that all variables have a significant influence on the dependent variable simultaneously. This can be proven from the $\mathrm{F}$ value of 39.922 with a probability value of 0.000 . Since probability is much less than 0.05 or $5 \%$, the regression model can be used to predict the GPA. 
Table 4. Assessment Test

\begin{tabular}{|c|c|c|c|c|c|c|}
\hline \multirow{2}{*}{\multicolumn{2}{|c|}{ Model }} & \multicolumn{2}{|c|}{$\begin{array}{c}\text { Unstandardized } \\
\text { Coefficients }\end{array}$} & \multirow{2}{*}{$\begin{array}{c}\text { Standardized } \\
\text { Coefficients }\end{array}$} & \multirow[b]{2}{*}{$\mathrm{t}$} & \multirow[b]{2}{*}{ Sig. } \\
\hline & & B & Std. Error & & & \\
\hline \multirow[t]{4}{*}{1} & (Constant) & 1.276 & .326 & & 3.915 & .000 \\
\hline & SWB & .083 & .065 & .124 & 1.272 & .045 \\
\hline & Moderated 2 & .020 & .013 & .148 & 1.503 & .034 \\
\hline & SC & 692 & .072 & .569 & 9.659 & .000 \\
\hline
\end{tabular}

a. Dependent Variable: $Y$

F :42,877 Sig. : 0.000 R Square : 0.356 Adjusted R Square : 0.346

$$
\begin{aligned}
& Y=a+b 1 X 2+b 2 X 3+b 3 \mathrm{M} 2 \\
& Y=1.276+0.124 X 1+0.569 X 3+0,148 \mathrm{M} 2
\end{aligned}
$$

Based on Table 4, the sig value of SWB regression coefficient is 0.045 smaller than the significant value of 0.05 , it means that the SWB has significantly affect the firm GPA. The first hypothesis states that SWB has a positive effect on firm value, is accepted. The sig value of SC regression coefficient is 0.000 smaller than the significant value of 0.05 . It suggests that self compassion has significantly affect the GPA, so the second hypothesis which states, the self compassion has a positive effect on the GPA, accepted

The sig value of Moderated regression analysis coefficient is 0.034 smaller than the significant value of 0.05 . third hypothesis which states that self compassion is a quasi variable and has positive effect on the GPA is accepted.

Table 4 shows the R Square value of 0.356 with Adjusted R2 of 0.346 . This shows that all independent and moderated variables, can explain $34.6 \%$ of the variation magnitude in the GPA. $65.4 \%$ of variations are explained by other variables that are not used in this study. Table 2 also shows that all variables have a significant influence on the dependent variable simultaneously. This can be proven from the $\mathrm{F}$ value of 42.877 with a probability value of 0.000 . Since probability is much less than 0.05 or $5 \%$, the regression model can be used to predict the GPA.

\section{Conclusions}

Based on the results of the research, the effect of PWB and SWB can be increasing on GPA of collages student whereas self-compassion can increase on GPA of collages student, conclusions PWB, SWB has a significant influence on GPA of collages student, and the results of this research proved that self-compassion variable is a quasi-moderating or self-compassion variable is an independent variable as well as a moderating variable.

\section{Research Limitations}

1. There are limitations to research using a questionnaire, that is, sometimes the answers given by respondents do not indicate the real situation.

2. The variables that affect GPA colage students used in this study consisted of only the PWB and SWB variables as independent and Self compassion as a moderate variables for the effect on GPA colage students, and Self compassion as a moderate variable while there are still many other variables that can affect GPA Collage student apart from Well being.

\section{References}

[1] K. D. Neff and A. P. Costigan, "Self-compassion, wellbeing, and happiness," Psychol. Osterr., 2014.

[2] C. L. M. Keyes, D. Shmotkin, and C. D. Ryff, "Optimizing well-being: The empirical encounter of two traditions," J. Pers. Soc. Psychol., 2002, doi: 10.1037/0022-3514.82.6.1007.

[3] C. D. Ryff and B. H. Singer, "Know thyself and become what you are: A eudaimonic approach to psychological well-being," J. Happiness Stud., 2008, doi: 10.1007/s10902-006-9019-0.

[4] E. Diener, "Subjective well-being: The science of happiness and a proposal for a national index," Am. 
Psychol., 2000, doi: 10.1037/0003-066X.55.1.34.

[5] S. R. Bukhari and S. J. Khanam, "Trait Emotional Intelligence As a Predictor of Academic Performance in University Students," J. Am. Coll. Surg., 2016, doi: 10.1016/j.jamcollsurg.2016.04.044.

[6] C. D. Ryff and C. L. M. Keyes, "The Structure of Psychological Well-Being Revisited," J. Pers. Soc. Psychol., 1995, doi: 10.1037/0022-3514.69.4.719.

[7] S. Oishi, E. Diener, and R. E. Lucas, "The optimum level of well-being," Perspect. Psychol. Sci., 2007.

[8] K. D. Neff, "Self-compassion, self-esteem, and well-being," Soc. Personal. Psychol. Compass, 2011, doi: 10.1111/j.1751-9004.2010.00330.x.

[9] Sumardi Suryabrata, "Metode penelitian," Metod. Penelit., 2014.

[10] Sekaran and Bougie, Research Method for Business Textbook (A Skill Building Approa). 2016.

[11] W. Pavot and E. Diener, "The Satisfaction With Life Scale and the emerging construct of life satisfaction," J. Posit. Psychol., 2008, doi: 10.1080/17439760701756946.

[12] D. Watson, L. a. Clark, and A. Tellegan, "Worksheet 3.1 The Positive and Negative Affect Schedule (PANAS; Watson et al., 1988) PANAS Questionnaire,” J. Pers. Soc. Psychol., 1988, doi: 10.1521/soco_2012_1006.

[13] K. D. Neff, "Self-Compassion Scale," Self Identity, vol. 2, no. October 2012, pp. 223-250, 2003, doi: $10.1080 / 15298860390209035$. 